\title{
Hoàn thiện quy trình phát hiện đồng thời 14 vi khuẩn gây bệnh đường ruột bằng kĩ thuật PCR-Reverse Dot Blot (PCR-RDB)
}

\section{Accomplishment of a protocol for simultaneous detection of 14 intestinal bacterial pathogens based on PCR-Reverse Dot Blot (PCR-RDB)}

\author{
Hồ Thị Thanh Thủy ${ }^{1}$, Nguyễn Văn Trường ${ }^{1}$, Nguyễn Bảo Toàn $^{2}$, Lao Đức Thuận ${ }^{3}$, \\ Trương Kim Phượng ${ }^{3}$, Lê Huyền Ái Thúy ${ }^{3 *}$ \\ ${ }^{1}$ Công ty Cổ phần và Công nghệ Việt Á, Việt Nam \\ ${ }^{2}$ Trung tâm chẩn đoán Y khoa Medic, Thành phố Hồ Chí Minh, Việt Nam \\ ${ }^{3}$ Trường Đại học Mở Thành phố Hồ Chí Minh, Việt Nam
}

*Tác giả liên hệ, Email: thuy.lha@ou.edu.vn

\section{THÔNG TIN}

DOI: 10.46223/HCMCOUJS. tech.vi.13.1.803.2018

Ngày nhận: 10/01/2018

Ngày nhận lại: 20/01/2018

Duyệt đăng: 14/03/2018

Tù khóa:

campylobacter jejuni, PCRReverse Dot Blot, vi khuẩn gây bệnh đường ruột, yersinia enterocolitica $0: 8$

\section{TÓM TÁT}

Ngộ độc thực phẩm, với một trong những nguyên nhân chính do nhiễm khuẩn vẫn luôn là mối lo ngại, mang tính toàn cầu, được Tổ chức Sức khỏe Thế giới rất quan tâm. Việc xác định chính xác đối tượng vi khuẩn nhiễm vẫn luôn là một nhu cầu cấp thiết của các labo lâm sàng. Nghiên cứu trước đây của chúng tôi đã được công bố với việc thành công ước đầu trong việc xây dựng một quy trình dựa trên kĩ thuật PCR-Reverse Dot Blot (PCR-RDB) nhằm ác đ nh đồng thời 12 vi khuẩn gây bệnh đường ruột ch yếu, bao gồm Bacillus cereus, Clostridium botulinum, Clostridium perfringen, Staphylococcus aureus, Listeria monocytogenes, Escherichia coli O157:H7, Salmonella spp., Shigella spp.., Vibrio cholerae, Vibrio parahaemolyticus, Yersinia enterocolitica và Brucella spp. Chúng tôi tiếp tục phát triển nghiên cứu này nhằm hoàn thiện quy trình $\mathrm{PCR}-\mathrm{RDB}$ bằng việc thiết kế ổ ung trên màng các loại mẫu dò nhằm làm chứng dương, chứng âm, chứng màu và chứng kiểm tra tín hiệu nền. Bên cạnh đó, xét nhu cầu lâm sàng, việc bổ sung hai loại mẫu dò đề dò hai vi khuẩn Campylobacter jejuni và Yersinia enterocolitica $\mathrm{O}: 8$ gây bệnh đường ruột chủ yếu ở trẻ em, là cần thiết. Quy trình PCR-RDB được hoàn thiện trong nghiên cứu này vì vậy có khả năng phát hiện đồng thời 14 vi khuẩn gây bệnh đường ruột, một cách đặc hiệu, với độ nhạy đạt $10^{2}$ bản $\mathrm{sao} / \mathrm{ml}$, đã được thử nghiệm trên 30 mẫu phân, ghi nhận kết quả hoàn toàn khớp với kít thương mại PowerCheck ${ }^{\mathrm{TM}} 20$ Pathogen Multiplex Real-time PCR Kit (Korea). 
Keywords:

campylobacter jejuni, intestinal bacteria, PCR-

Reverse Dot Blot, yersinia enterocolitica O:8

\section{ABSTRACT}

Food poisoning, caused by a bacterial infection, consequently led to a wide range of infections and endanger to public health, has been considered as a big concern in the world. Therefore, it is an urgent demand for the clinical laboratory to exactly identify infectious bacteria. In our previous study, we successfully published a protocol based on the PCR-Reverse Dot Blot (PCR-RDB) to determine simultaneously 12 bacterial intestinal pathogens, including Bacillus cereus, Clostridium botulinum, Clostridium perfringen, Staphylococcus aureus, Listeria monocytogenes, Escherichia coli O157: H7, Salmonella spp., Shigella spp.., Vibrio cholerae, Vibrio parahaemolyticus, Yersinia enterocolitica and Brucella spp. In this study, we continuously developed our published protocol by designing additional probes: positive control probe, negative control probe, color control probe and background signal controller. Moreover, concerning the clinical demand, the supplement of two designed probes, which detected Campylobacter jejuni và Yersinia enterocolitica O:8 caused intestinal infected diseases mainly in children, was necessary. As a result, this completed PCR-RDB protocol can simultaneously detect a total of 14 intestinal bacterial pathogens within high specificity and the sensitivity of $10^{2}$ copies $/ \mathrm{ml}$. For the protocol confirmation, it was tested by 30 fecal samples and the results completely match with the commercial kit PowerCheckTM 20 Pathogen Multiplex Realtime PCR Kit (Korea).

\section{Mở đầu}

Ngộ độc thực phẩm đã và đang là một trong những vấn đề mang tính toàn cầu được Tổ chức Sức khỏe Thế giới (World Health Organization - WHO và Trung tâm Phòng và Kiểm soát bệnh của Mỹ (US Center for Disease Control and Prevention - CDC công bố hằng năm với những con ố nhiễm khuẩn và ngộ độc từ thực phẩm rất lớn. Triệu chứng lâm sàng củaa các đối tượng nhiễm thường là nôn mửa và tiêu chảy, tuy nhiên đa số trường hợp là không phân biệt được nếu dựa trên triệu chứng lâm sàng bởi vi khuẩn nhiễm rất khác nhau. Chính vì vậy, việc xác định chính xác vi khuẩn nhiễm là một nhu cầu cấp thiết của các labo lâm sàng. Các kỹ thuật hiện nay đang được áp dụng tại các bệnh viện chủ yếu dựa trên nuôi cấy vi khuẩn. Mặc dù đây là chuẩn vàng của xác định vi khuẩn nhiễm, nhưng cả quy trình đòi hỏi thời gian dài để thu nhận kết quả. Chính yếu tố thời gian này đã làm ảnh hưởng đến việc lựa chọn phương pháp điều trị kịp thời và thích hợp cho bệnh nhân. Vì vậy, một phương pháp nhanh, nhạy và đặc hiệu để xác định chính xác các vi khuẩn gây bệnh thực sự là một nhu cầu cấp bách. 
Trong những năm vừa qua, kỹ thuật Sinh học Phân tử đã có những ứng dụng hết sức cụ thể và cần thiết trong lĩnh vực chẩn đoán vi sinh, như vi sinh lâm sàng, kiểm nghiệm thực phẩm, ..., chủ yếu là PCR và các cải biên từ PCR; trong số đó, PCR kết hợp với lai phân tử, điển hình như PCR kết hợp lại ngược theo từng lỗ trên màng (Reverse Dot Blot hybridization - RDB hybridization) với tính chất đơn giản, dễ tự động hóa, nên việc triển khai trong lâm sàng đã được thực hiện. Công bố trước đây của chúng tôi đã cung cấp thông tin của hai cặp mồi chung và 12 mẫu dò đặc hiệu để dò 12 loại vi khuẩn gây bệnh đường ruột phổ biến bao gồm Bacillus cereus, Clostridium botulinum, Clostridium perfringen, Staphylococcus aureus, Listeria monocytogenes, Escherichia coli O157:H7, Salmonella spp., Shigella spp.., Vibrio cholerae, Vibrio parahaemolyticus, Yersinia enterocolitica và Brucella spp (Thuy, Thuan, Phuong, \& Thuy, 2016). Tại Việt Nam, Salmonella cùng với Campylobacter và Shigella là ba tác nhân vi khuẩn gây bệnh quan trọng trong tiêu chảy trẻ em, trong đó, Campylobacter jejuni là loài gây tiêu chảy rất phổ biến bởi nguồn lây nhiễm chủ yếu là từ gia cầm và các sản phẩm gia cầm (Blessmann et al., 2002; Bộ Y tế, 2009; WHO, 2005), lợn và các gia súc khác (Nguyen, Van, Huy, Gia, \& Weintraub, 2006; Schroeder \& Hilbi, 2008; Vinh, 2010; WHO, 2013). Một số công bố cho thấy nhiễm Campylobacter ở trẻ em Việt Nam dao động từ 2 - 4\% (Katherine et al., 2015; Thompson et al., 2015) và dưới 1\% ở người lớn (Trang, Hien, Molbak, Cam, \& Dalsgaard, 2007), trong đó Campylobacter là nguồn nhiễm phổ biến nhất ở trẻ em nông thôn, chiếm đến $31 \%$ các trường hợp nhiễm khuẩn (Isenbarger et al., 2001). Có đến $15-30 \%$ các mẫu thịt được lấy từ các vùng khác nhau, tại Việt Nam, ghi nhận nhiễm Campylobacter (Carrique-Mas et al., 2014; Garin et al., 2012; Huong, Hanh, Cam, \& Be, 2006; Ha \& Pham, 2006; Schwan, 2010), thịt vịt và thịt lợn nhiễm Campylobacter tương ứng 23,9 và 53,7\% (Carrique-Ma et al., 2014); 35,1\% các mẫu thịt gà thu tại quầy và các cơ sở giết mỗ nhiễm Campylobacter jejuni (Bao et al., 2006). Chính vì vậy, việc bổ sung Campylobacter jejuni vào trong số 14 loài vi khuẩn đích phát hiện của nghiên cứu này là rất cần thiết. Bên cạnh đó, vi khuẩn Yersinia enterocolitica O:8 là serotype thuộc nhóm gây độc mạnh (Fredriksson-Ahomaa \& Korkeala, 2003; Fukushima, Shimizu, \& Inatsu, 2011; Huovinen et al., 2010) nhưng mẫu dò YER trong công bố trước của chúng tôi (Thuy et al., 2016), chưa dò đặc hiệu cho serotype này. Vì thế việc thiết kế thêm một mẫu dò nữa bắt cặp đặc hiệu riêng với Yersinia enterocolitica O:8, đã được đặt ra thêm trong nghiên cứu này.

Ngoài ra, để hoàn thiện quy trình, cần phải bổ sung trên màng các loại mẫu dò nhằm làm chứng dương, chứng âm, chứng màu và chứng kiểm tra tín hiệu nền là rất cần thiết. Nghiên cứu này vì vậy được đặt ra với mục đích là thiết kế mới hai mẫu dò để dò hai vi khuẩn Campylobacter jejuni và Yersinia enterocolitica $\mathrm{O}: 8$, nâng tổng số vi khuẩn gây bệnh đường ruột có thể phát hiện lên thành 14 , bên cạnh việc hoàn thiện quy trình PCR-RDB bằng việc bổ sung các loại mẫu dò chứng dương, chứng âm, chứng màu và chứng nền, trước khi thử nghiệm quy trình trên một số mẫu phân và so sánh với kít thương mại nhập từ Hàn Quốc.

\section{Vật liệu - Phương pháp}

\subsection{Vi khuẩn chuẩn}

14 loài vi khuẩn gây bệnh đường ruột được thu thập từ ngân hàng giống ATCC, bao gồm: Salmonella spp., Shigella spp., Escherichia coli O157:H7, Bacillus cereus, Vibrio 
parahaemolyticus, Vibrio cholerae, Listeria monocytogenes, Staphylococcus aureus, Clostridium botulinum, Clostridium perfringens, Yersinia enterocolitica, Brucella spp., Yersinia enterocolitica $\mathrm{O}: 8$ và Campylobacter jejuni.

\subsection{Bệnh phẩm}

30 mẫu phân thu thập từ Trung tâm chẩn đoán Y khoa Medic, Thành phố Hồ Chí Minh.

\subsection{Mồi và mấu dò}

Các bộ mồi chung và 12 mẫu dò để dò 12 vi khuẩn Clostridium botulinum, Clostridium perfringen, Staphylococcus aureus, Listeria monocytogenes, Escherichia coli O157:H7, Salmonella spp., Shigella spp.., Vibrio cholerae, Vibrio parahaemolyticus, Yersinia enterocolitica và Brucella spp (Thuy et al., 2016); cùng với các mẫu dò để dò 2 vi khuẩn Campylobacter jejuni và Yersinia enterocolitica $\mathrm{O}: 8$, mẫu dò dùng làm chứng dương, chứng âm, chứng màu (Bảng 1), được đặt tổng hợp tại IDT, Mỹ.

\subsection{Chuẩn bị mẫu bệnh phẩm và mẫu tế bào nuôi cấy}

Mẫu phân được thu nhận và chuyển đến phòng vi sinh, Công ty Cổ phần \& Công nghệ Việt Á ở điều kiện nhiệt độ $\mathrm{t} 4-8^{\circ} \mathrm{C}$. Lấy $100 \mathrm{mg}$ phân rắn hoặc $200 \mu$ l phân lỏng đồng nhất trong 1ml TE 1X (Tris-EDTA); Ly tâm 2800 vòng trong 2 phút thu $200 \mu 1$ dịch nổi hoặc lấy $200 \mu 1$ dịch tế bào vi khuẩn nuôi cấy, thêm vào $900 \mu 1$ dung dịch Trizol, vorte 30 , để yên ở nhiệt độ phòng trong 10 phút; Thêm vào $200 \mu$ l dung dịch Chloroform, ly tâm 13000 vòng/phút trong

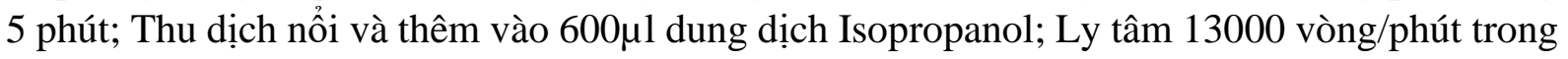
5 phút, thu cặn màu xanh; Thêm 900ul dung dịch Ethanol 70 \%, ly tâm 13000 vòng/phút trong 2 phút, hòa tan cặn trong $50 \mu 1$ dung dịch TE $1 X$. Hóa chất tách chiết này là sản phẩm kít của đề tài nghiên cứu khoa học cấp Bộ Giáo dục Đào tạo (B2015-32-03): ${ }^{N A} a D N A$ Extraction Kit P (Việt Á).

\subsection{PCR-RDB}

PCR được thực hiện với máy MxproMx3005P (Stratagene , thành phần như sau: $2 \mu 1$ 16S/23S qPCR Mix 10X [10X Hot Start PCR Buffer, Maxima Hot Start Taq DNA Polymerase $(5 \mathrm{U} / \mu \mathrm{L}), 25 \mathrm{mM} \mathrm{MgCl} 2, \mathrm{dNTP} \operatorname{mix} 200 \mu \mathrm{M}$, hỗn hợp 4 mồi $0,5 \mu \mathrm{M}, 20 \mathrm{ng}$ DNA và nước cất đủ thể tích $20 \mu 1$. Chương trình nhiệt ao gồm: 1 chu kỳ: $95^{\circ} \mathrm{C}-5$ phút; 40 chu kỳ: $94^{\circ} \mathrm{C}-30$ giây, $55^{\circ} \mathrm{C}-45$ giây (chọn đọc kết quả tại ước này), $72^{\circ} \mathrm{C}-45$ giây; 1 chu kỳ: $72^{\circ} \mathrm{C}-6$ phút; 1 chu kỳ: $72^{\circ} \mathrm{C}-30$ giây (chọn đọc kết quả tại ước này); 1 chu kỳ: $95^{\circ} \mathrm{C}-30$ giây.

Việc chuẩn bị màng lai, gắn các mẫu dò oligonucleotide lên màng được thực hiện như sau: Màng được rửa nhanh với $\mathrm{HCl}(0.1 \mathrm{~mol} / \mathrm{l})$, sau đó được xử lý với 20\% EDC (1-ethyl-3-[3dimethylaminopropyl] trong nước khử ion, tiếp theo đó rửa với nước khử ion một lần nữa. Mẫu dò biến đổi có gắn thêm nhóm amino acid ở đầu $5^{\prime}$ ' được hòa trong $0.5 \mathrm{~mol} / 1$ sodium bicarbonate buffer (pH 8.4), sau đó chấm vào những vị trí đã ghi định vị sẵn trên màng. Nhóm amino của mẫu dò sẽ gắn với nhóm carboxyl trên màng. Những điểm chấm trên màng được rửa với Tri bufferes saline/0.1\% Tween-20. Cuối cùng màng sẽ được rửa với nước khử ion và làm khô để bảo quản hoặc là sử dụng ngay. 
RDB được thực hiện với các điều kiện cơ bản như sau: biến tính $10 \mu 1$ sản phẩm PCR trong 30 phút, nhiệt độ phòng, với dung dịch $\mathrm{NaOH} 0,5 \mathrm{~N}$; lai trong 3 giờ ở $40^{\circ} \mathrm{C}$, sau đó rửa màng lai trong 20 phút và phát hiện tín hiệu lai sau 30-45 phút với dung dich phát hiện (NBT/BCIP), trong tối.

Hóa chất PCR-RDB này là các sản phẩm kít của đề tài nghiên cứu khoa học cấp Bộ Giáo dục Đào tạo (B2015-32-03): RDB 16S/23SFR - rPCR kit và RDB Hybridization - Solution kit (Việt Á).

\section{Bảng 1}

Thông tin về các mồi và mẫu dò

\begin{tabular}{|c|c|c|c|c|}
\hline STT & $\begin{array}{l}\text { Mồi/ } \\
\text { Mẫu } \\
\text { dò }\end{array}$ & Trình tự $\left(5^{\prime} \rightarrow 3^{\prime}\right)$ & Vi khuẩn dò & $\begin{array}{c}\text { Chiều } \\
\text { dài }\end{array}$ \\
\hline 1 & $16 \mathrm{SF}$ & CTGGCGGCAGGCCTAACACAT & \multirow{2}{*}{ Chung } & 21 \\
\hline 2 & $16 \mathrm{SR}$ & GGCTGCTGGCACGGAGTTAG & & 20 \\
\hline 3 & $23 \mathrm{SR}$ & ACCGATAGTGAACCAGTACCGTGAG & \multirow{2}{*}{ Chung } & 25 \\
\hline 4 & $23 \mathrm{SF}$ & TTAAATGATGGCTGCTTCTAAGCC & & 24 \\
\hline 5 & $\mathrm{BAC}$ & TGCTAGTTGCTGGGAATAACACCTTGACG & B. cereus & 29 \\
\hline 6 & BRU & $\begin{array}{l}\text { CGTAGAATAACTCAGGGCCATTTGCTACG } \\
\text { AAACTTGTG }\end{array}$ & Brucella spp. & 38 \\
\hline 7 & $\mathrm{CBO}$ & $\begin{array}{l}\text { TATAAGAGATTTTCTTATGAATCGCATCC } \\
\text { AAAGATTTAT }\end{array}$ & C. botulinum & 39 \\
\hline 8 & $\mathrm{CPF}$ & $\begin{array}{l}\text { ATGGCATCATAAAGGAGCAATCCGCCATT } \\
\text { CAACCTATGAGATGGACCC }\end{array}$ & $\begin{array}{l}\text { C. } \\
\text { perfringens }\end{array}$ & 48 \\
\hline 9 & LIS & $\begin{array}{l}\text { TGTTGTTAAAGGATAAGAGGAGAAGAAC } \\
\text { TAACTGCT }\end{array}$ & $\begin{array}{l}L . \\
\text { monocytogen } \\
\text { es }\end{array}$ & 36 \\
\hline 10 & SAL & $\begin{array}{l}\text { GGTGTTGTCGCAGCAAGGTTAATAACTTG } \\
\text { A }\end{array}$ & $\begin{array}{l}\text { Salmonella } \\
\text { spp. }\end{array}$ & 30 \\
\hline 11 & SHI & $\begin{array}{l}\text { GGGAGTAACTTTGCTCAGTTAATACATTG } \\
\text { A }\end{array}$ & Shigella spp. & 30 \\
\hline 12 & SAU & $\begin{array}{l}\text { ACATATGTTGTGCACAGTAAGTAACTCTT } \\
\text { GACGGTA }\end{array}$ & S. aureus & 36 \\
\hline 13 & VPA & $\begin{array}{l}\text { AAACGACTTCGGGGAAGTTATCTGAACC } \\
\text { GATAACGG }\end{array}$ & $\begin{array}{l}V . \\
\text { parahaemolyt } \\
\text { icus }\end{array}$ & 36 \\
\hline
\end{tabular}




\begin{tabular}{|c|c|l|l|c|}
\hline STT & $\begin{array}{c}\text { Mồi/ } \\
\text { Mẫu } \\
\text { dò }\end{array}$ & \multicolumn{1}{|c|}{ Trình tự $\left(\mathbf{5}^{\prime} \rightarrow \mathbf{3}^{\prime}\right)$} & Vi khuẩn dò & $\begin{array}{c}\text { Chiều } \\
\text { dài }\end{array}$ \\
\hline 14 & VCH & $\begin{array}{l}\text { CAGCACACTTGGGTGAGGAACTTGTTCGG } \\
\text { CGAG }\end{array}$ & V. cholerae & 33 \\
\hline 15 & YER & $\begin{array}{l}\text { CATAAATTTGTGATTGGTTAATAACCGAC } \\
\text { GT }\end{array}$ & $\begin{array}{l}\text { Y. } \\
\text { enterocolitica }\end{array}$ & 24 \\
\hline 16 & ECO & $\begin{array}{l}\text { AGACAGCCATTAGAAGGGATGTTGGCCA } \\
\text { GCCA }\end{array}$ & $\begin{array}{l}\text { E. coli } \\
\text { O157:H7 }\end{array}$ & 28 \\
\hline 17 & YO8 & $\begin{array}{l}\text { CCAATAATTGGATTGACCTTAATACGTTG } \\
\text { GT }\end{array}$ & $\begin{array}{l}\text { Y. } \\
\text { enterocolitica } \\
\text { O:8 }\end{array}$ & 31 \\
\hline 18 & CJE & $\begin{array}{l}\text { AAGTGGGCGTTTCATCCTCCACGCGCTGC } \\
\text { G }\end{array}$ & C. jejuni & 30 \\
\hline 19 & P & TTTGGCTAACTCCGTGCCAGCAGCCGCG & Chứng dương & 28 bp \\
\hline 20 & C & $\begin{array}{l}\text { BIOTIN- } \\
\text { CCGCTGTATCACAAGGGCTGGTACCTTT }\end{array}$ & Chứng màu & 28 bp \\
\hline 21 & N & TTTCCGCTGTATCACAAGGGCTGGTACC & Chứng âm & 28 bp \\
\hline 22 & B & 0.5mol/L sodium bicarbonate buffer & Tín hiệu nền & No \\
\hline
\end{tabular}

Nguồn: Kết quả phân tích dữ liệu của nhóm nghiên cứu

\section{Kết quả và thảo luận}

\subsection{Khảo sát độ đặc hiệu của các mẫu dò trên máy tính}

Trình tự $16 \mathrm{~S}$ rRNA gen của các vi khuẩn Campylobacter jejuni và Yersinia enterocolitica $\mathrm{O}: 8$ được thu nhận từ Genbank, so sánh để ghi nhận vùng tương đồng; từ đó vùng tương đồng thuộc trình tự được khuếch đại ởi các mồi chung (Bảng 1 được nhận diện. Trình tự các mẫu dò để dò các vi khuẩn Campylobacter jejuni và Yersinia enterocolitica $\mathrm{O}: 8$ được cân nhắc chọn (Bảng 1). Ngoài ra, trình tự bảo tồn chung cho cả 14 vi khuẩn khảo át cũng được chọn làm mẫu dò chứng dương, chứng nền; $\mathrm{v}$ ng khác iệt được chọn làm mẫu dò chứng âm được trình bày như ở Bảng 1 .

Phần mềm Blast tích hợp trên cơ ở dữ liệu NCBI được ử dụng để đánh giá độ đặc hiệu của các mẫu dò mới được thiết kế trong nghiên cứu này, ghi nhận tính đặc hiệu tuyệt đối của hai mẫu dò để dò hai vi khuẩn Campylobacter jejuni và Yersinia enterocolitica $\mathrm{O}: 8$, cũng như các mẫu dò dùng làm chứng dương, chứng âm, chứng màu (dữ liệu không trình bày. Thêm vào đó, các tính chất vật lý của các mẫu dò được kiểm tra bằng công cụ "Analyzer" tích hợp trên trang web của IDT: http://www.idtdna.com/analyzer/ Applications/OligoAnalyzer. Kết quả cho thấy các giá trị $\Delta \mathrm{G}$ của các mẫu dò để dò vi khuẩn Campylobacter jejuni (CJE), Yersinia enterocolitica $\mathrm{O}: 8$ (YO8), chứng dương $(\mathrm{P})$, chứng màu $(\mathrm{C})$ và chứng âm $(\mathrm{N})$ đều đạt, một số 
giá trị nhỏ hơn $<-9$ kcal.mole ${ }^{-1}$ nhưng không nhỏ hơn nhiều (Bảng 2, vì thế cũng sẽ không ảnh hưởng đến các thí nghiệm về sau, đăc biệt là phản ứng lai.

\section{Bảng 2}

Các thông ố vật lý của các mẫu dò

\begin{tabular}{|c|c|c|c|c|c|c|c|}
\hline STT & $\begin{array}{c}\text { Ký hiệu } \\
\text { mấu dò }\end{array}$ & \multicolumn{1}{|c|}{ Trình tự (5' - 3') } & $\begin{array}{c}\text { Chiều } \\
\text { dài (bp) }\end{array}$ & \% GC & $\begin{array}{c}\text { Tm } \\
\left.\mathbf{(}^{\circ} \mathbf{C}\right)\end{array}$ & $\mathbf{1}$ & $\mathbf{2}$ \\
\hline 1 & CJE & $\begin{array}{l}\text { AAGTGGGCGTTTCAT } \\
\text { CCTCCACGCGCTGCG }\end{array}$ & 30 & 63,3 & 70,2 & $-2,49$ & $-10,36$ \\
\hline 2 & YO8 & $\begin{array}{l}\text { CCAATAATTGGATTG } \\
\text { TCCTTATACGTTGG }\end{array}$ & 31 & 35,5 & 57,4 & $-2,24$ & $-8,44$ \\
\hline 3 & P & $\begin{array}{l}\text { TTTGGCTAACTCCGT } \\
\text { GCCAGCAGCCGCG }\end{array}$ & 28 & 64,3 & 69,7 & $-2,36$ & $-10,36$ \\
\hline 4 & $\mathrm{C}$ & $\begin{array}{l}\text { CCGCTGTATCACAAG } \\
\text { GGCTGGTACCTTT }\end{array}$ & 28 & 53,6 & 63,7 & $-0,96$ & $-9,78$ \\
\hline 5 & $\mathrm{~N}$ & $\begin{array}{l}\text { TTTCCGCTGTATCAC } \\
\text { AAGGGCTGGTACC }\end{array}$ & 28 & 53,6 & 63,7 & 0,04 & $-9,78$ \\
\hline
\end{tabular}

Ghi chú: (1): Năng lượng $\Delta \mathrm{G}\left(\mathrm{kcal}^{\mathrm{m}} \mathrm{mole}{ }^{-1}\right)$ hình thành cấu trúc kẹp tóc (hairpin) của mẫu dò

(2): Năng lượng $\Delta \mathrm{G}$ (kcal.mole $\left.{ }^{-1}\right)$ hình thành cấu trúc tự bắt cặp (self-dimer) của mẫu dò

Nguồn: Kết quả phân tích dữ liệu của nhóm nghiên cứu

Nhiệt độ nóng chảy của 5 mẫu dò tổng hợp mới trong nghiên cứu này thay đổi trong khoảng từ 57,4 đến $70,2^{\circ}$, cũng như không quá khác biệt so với 12 mẫu dò đã công bố trước đây (Thuy et al., 2016), thay đổi trong khoảng từ 56,9 đến $68,6^{\circ} \mathrm{C}$. Sự thay đổi này hoàn toàn có thể đáp ứng được điều kiện thực nghiệm của phản ứng lai.

\subsection{Khảo sát độ đặc hiệu và độ nhạy của các mẫu dò trên thục nghiệm}

Với điều kiện lai như đã được nêu trong phần vật liệu và phương pháp, sản phẩm PCR từ DNA của 14 vi khuẩn chuẩn được lai thử nghiệm trên giả mẫu (với mẫu phân), theo các dãy nồng độ vi khuẩn từ $10^{0}$ đến $10^{6}$, ghi nhận độ nhạy của quy trình PCR-RDB đạt ở mức $10^{2}$ bản sao/ml (Hình 1). Để dễ theo dõi, bảng sau (Bảng 3) ghi chú lại sơ đồ vị trí các mẫu dò được cố định trên mỗi màng lai. 


\section{Bảng 3}

Sơ đồ vị trí các mẫu dò được cố định trên màng lai

\begin{tabular}{|c|c|c|c|c|c|}
\hline & $\mathbf{1}$ & $\mathbf{2}$ & $\mathbf{3}$ & $\mathbf{4}$ & $\mathbf{5}$ \\
\hline $\mathbf{A}$ & Chứng dương & Chứng nền & Chứng âm & Chứng màu & BAC \\
\hline $\mathbf{B}$ & BRU & CBO & CPF & LIS & SAL \\
\hline C & SHI & SAU & VPA & VCH & YER \\
\hline D & ECO & YO8 & CJE & & \\
\hline
\end{tabular}

Nguồn: Kết quả phân tích dữ liệu của nhóm nghiên cứu
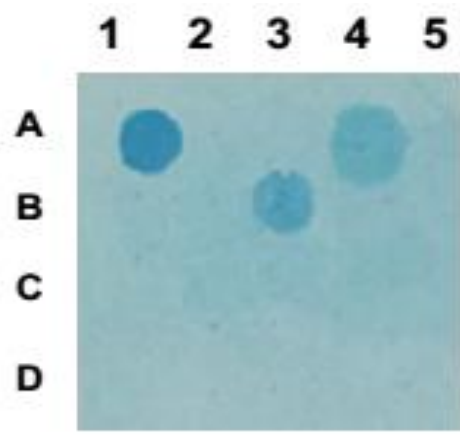

CPF

\section{$\begin{array}{lllll}1 & 2 & 3 & 4 & 5\end{array}$}

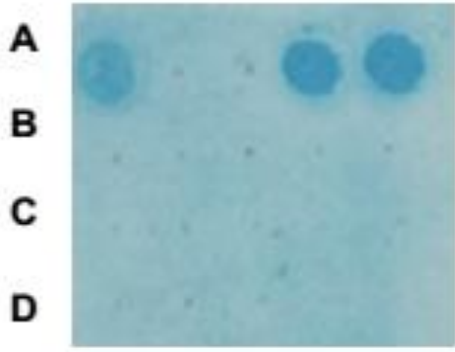

BAC

\section{$\begin{array}{lllll}1 & 2 & 3 & 4 & 5\end{array}$}

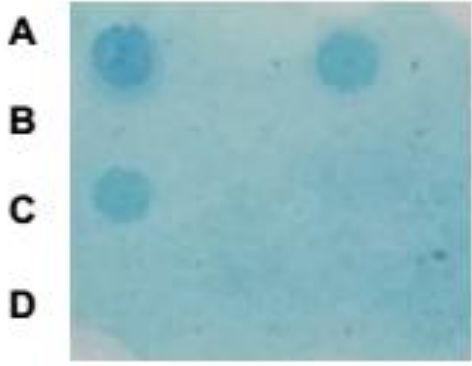

SHI $\begin{array}{lllll}1 & 2 & 3 & 4 & 5\end{array}$

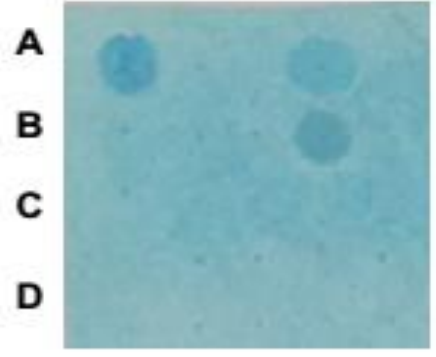

LIS

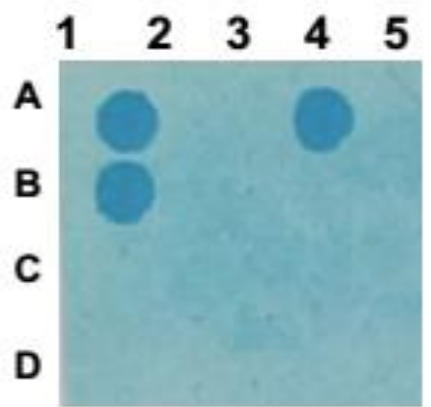

BRU
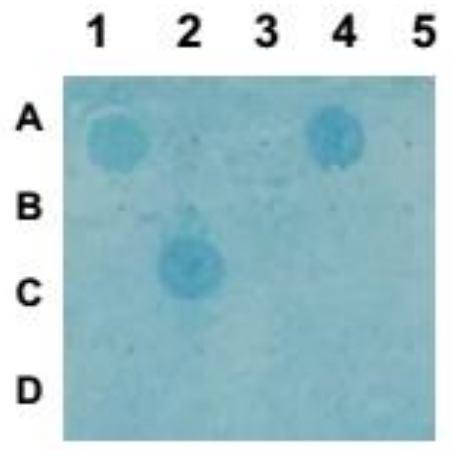

SAU $\begin{array}{lllll}1 & 2 & 3 & 4 & 5\end{array}$
A
B
C
D

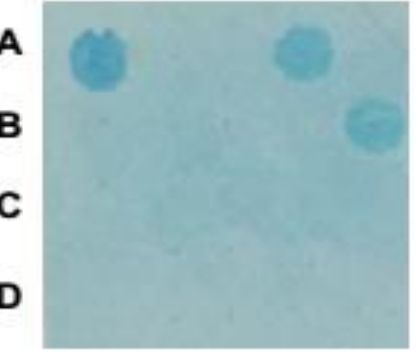

SAL

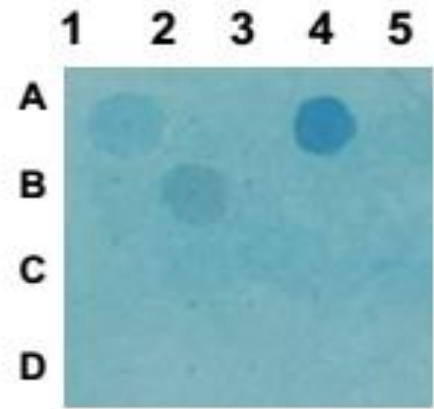

CBO

$\begin{array}{lllll}1 & 2 & 3 & 4 & 5\end{array}$

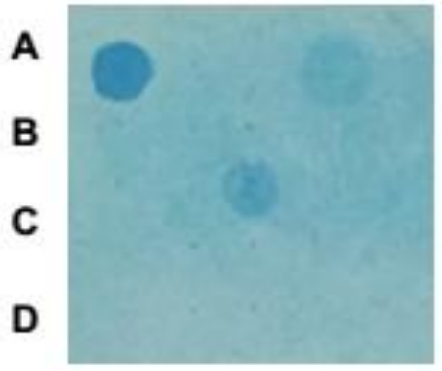

VPA 


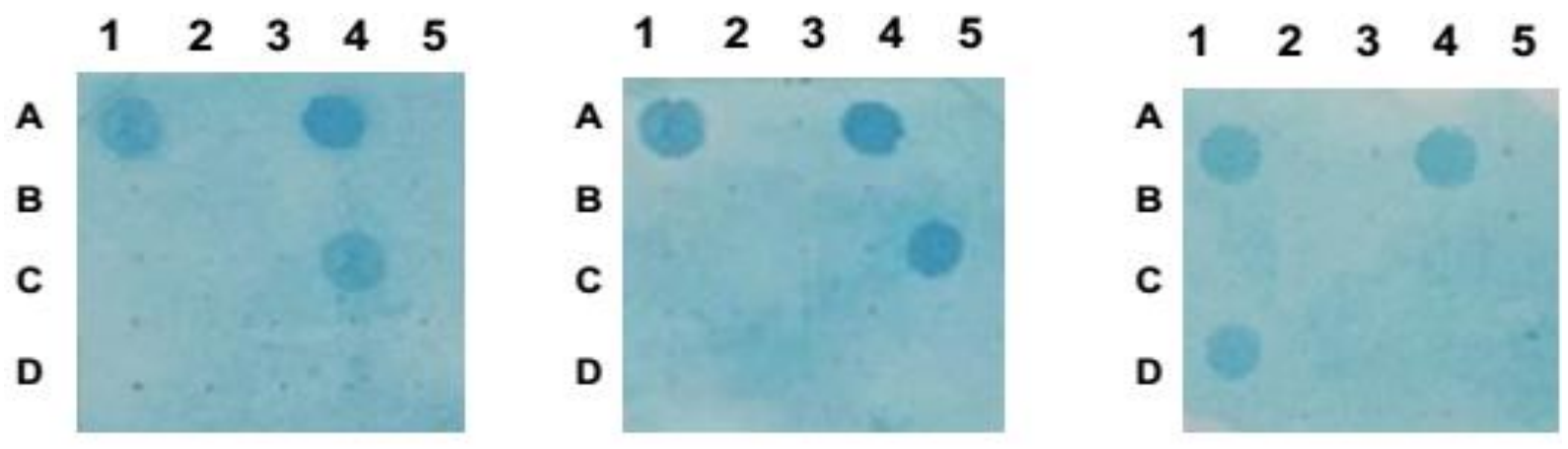

VCH

YER

ECO

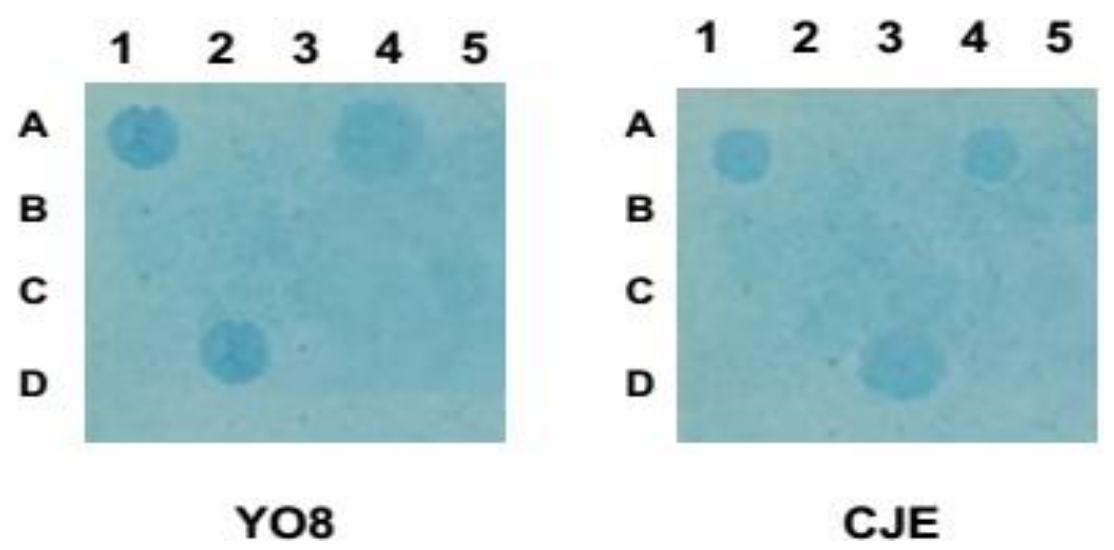

Hình 1. Kết quả PCR-RDB cho độ nhạy $10^{2}$ bản sao/ml tương ứng với 14 mẫu phân nhiễm 14 vi khuẩn

Kết quả trên (Hình 1) cũng đồng thời khẳng định tính đăc hiệu của các mẫu dò: 14 sản phẩm lai hoàn toàn đặc hiệu tương ứng với 14 chủng vi khuẩn đích, không ghi nhận bất kỳ dấu hiệu nào cho thấy có sự bắt chéo giữa các mẫu dò và vi khuẩn. Các tín hiệu tương ứng với các vị trí của chứng dương và chứng màu đều rõ ràng, chứng âm và chứng nền đều không xuất hiện bất cứ tín hiệu nào. Hơn nữa, 14 sản phẩm PCR được thực hiện từ DNA tách từ 14 vi khuẩn chuẩn đều được giải trình tự, ghi nhận tính đặc hiệu hoàn toàn của sản phẩm giải được (dữ liệu không trình bày), cho phép chúng tôi khẳng định tính khuếch đại đặc hiệu của hai cặp mồi chung (Thuy et al., 2016).

\subsection{Thử nghiệm quy trình PCR-RDB trên mẫu lâm sàng}

Thử nghiệm quy trình PCR-RDB phát hiện đồng thời 14 vi khuẩn gây bệnh đường ruột trên 30 mẫu phân thu nhận tại Trung tâm Chẩn đoán Y khoa medic, Thành phố Hồ Chí Minh, kết quả ghi nhận 10 mẫu dương, trong đó các mẫu 1 và 20 nhiễm đồng thời hai vi khuẩn: mẫu 1 đồng nhiễm Salmonella spp và Bacillus aureus; mẫu 20 đồng nhiễm Shigella spp và Staphylococcus aureus (Bảng 4, Hình 2). Kết quả thử nghiệm này cũng được chúng tôi kiểm tra bằng bộ kít thương mại PowerCheck ${ }^{\mathrm{TM}} 20$ Pathogen Multiplex Real-time PCR Kit (Korea), ghi nhận tính tương đồng tuyệt đối trong cả 30 mẫu (Bảng 4). 


\section{Bảng 4}

Kết quả thử nghiệm trên 30 mẫu phân

\begin{tabular}{|c|c|c|c|c|c|c|c|}
\hline & \multirow{2}{*}{$\begin{array}{l}\text { PCR- } \\
\text { RDB }\end{array}$} & \multicolumn{6}{|c|}{ PowerCheck $^{\mathrm{TM}} 20$ Pathogen Multiplex Real-time PCR Kit } \\
\hline Mẫu & & $\begin{array}{c}\text { Multiplex } \\
1 \text { Set }\end{array}$ & $\begin{array}{c}\text { Multiplex } \\
2 \text { Set }\end{array}$ & $\begin{array}{l}\text { Multiplex } 3 \\
\text { Set }\end{array}$ & $\begin{array}{l}\text { Multiplex } 4 \\
\text { Set }\end{array}$ & $\begin{array}{c}\text { Multiplex } \\
5 \text { Set }\end{array}$ & $\begin{array}{c}\text { Multiplex } \\
6 \text { Set }\end{array}$ \\
\hline Mẫu 1 & $\begin{array}{c}\text { Salmone } \\
\qquad \text { lla } \\
\text { B. } \\
\text { cereus }\end{array}$ & & & $\begin{array}{c}\text { IC (Ct 26) } \\
\text { Salmonella } \\
(C t 26)\end{array}$ & $\begin{array}{c}\text { B.cereus (Ct } \\
38)\end{array}$ & & \\
\hline Mẫu 2 & C. jejuni & $\begin{array}{c}C . \\
\text { jejuni } \\
\text { (Ct 25) }\end{array}$ & & $I C(C t 26)$ & & & \\
\hline Mẫu 3 & Shigella & & & $I C(C t 26)$ & & & $\begin{array}{c}\text { EIEC } \\
(\text { ipaH) } \\
(C t \text { 19) }\end{array}$ \\
\hline Mẫu 4 & $\begin{array}{c}\text { Salmone } \\
\text { lla }\end{array}$ & & & $\begin{array}{c}\text { IC (Ct 26) } \\
\text { Salmonella } \\
(\text { Ct 26) }\end{array}$ & & & \\
\hline Mẫu 5 & $\begin{array}{c}S . \\
\text { aureus }\end{array}$ & & & $I C(C t 26)$ & $\begin{array}{c}\text { S. aureus } \\
\text { (Ct 35) }\end{array}$ & & \\
\hline Mẫu 6 & $\begin{array}{l}\text { Salmone } \\
\text { lla }\end{array}$ & & & $\begin{array}{c}\text { IC (Ct 26) } \\
\text { Salmonella } \\
\text { (Ct 29) }\end{array}$ & & & \\
\hline Mẫu 7 & - & & & $I C(C t 26)$ & & & \\
\hline Mẫu 8 & - & & & $I C(C t 26)$ & & & \\
\hline Mẫu 9 & - & & & $I C(C t 26)$ & & & \\
\hline $\begin{array}{c}\text { Mẫu } \\
10\end{array}$ & - & & & $I C(C t 26)$ & & & \\
\hline $\begin{array}{c}\text { Mẫu } \\
11\end{array}$ & - & & & $I C(C t 26)$ & & & \\
\hline $\begin{array}{c}\text { Mẫu } \\
12\end{array}$ & - & & & $I C(C t 25)$ & & & \\
\hline
\end{tabular}




\begin{tabular}{|c|c|c|c|c|c|c|c|}
\hline & \multirow{2}{*}{$\begin{array}{l}\text { PCR- } \\
\text { RDB }\end{array}$} & \multicolumn{6}{|c|}{ PowerCheck $^{\text {TM }} 20$ Pathogen Multiplex Real-time PCR Kit } \\
\hline Mẫu & & $\begin{array}{l}\text { Multiplex } \\
1 \text { Set }\end{array}$ & $\begin{array}{c}\text { Multiplex } \\
2 \text { Set }\end{array}$ & $\begin{array}{l}\text { Multiplex } 3 \\
\text { Set }\end{array}$ & $\begin{array}{l}\text { Multiplex } 4 \\
\text { Set }\end{array}$ & $\begin{array}{l}\text { Multiplex } \\
5 \text { Set }\end{array}$ & $\begin{array}{c}\text { Multiplex } \\
6 \text { Set }\end{array}$ \\
\hline $\begin{array}{c}\text { Mẫu } \\
13\end{array}$ & - & & & $I C(C t 26)$ & & & \\
\hline $\begin{array}{c}\text { Mẫu } \\
14\end{array}$ & $\begin{array}{l}\text { L.monoc } \\
\text { ytogenes }\end{array}$ & & & $\begin{array}{c}\text { IC (Ct 25) } \\
\text { L.monocyto } \\
\text { genes } \\
\text { (Ct 31) }\end{array}$ & & & \\
\hline $\begin{array}{c}\text { Mẫu } \\
15\end{array}$ & $\begin{array}{c}\text { E. coli } \\
\text { O157:H } \\
7 \\
\end{array}$ & & & $I C(C t 26)$ & & & $\begin{array}{l}E A E C \\
(\text { aggR) } \\
(C t 31)\end{array}$ \\
\hline $\begin{array}{c}\text { Mẫu } \\
16 \\
\end{array}$ & - & & & $I C(C t 26)$ & & & \\
\hline $\begin{array}{c}\text { Mẫu } \\
17 \\
\end{array}$ & - & & & $I C(C t 26)$ & & & \\
\hline $\begin{array}{c}\text { Mẫu } \\
18\end{array}$ & - & & & $I C(C t 25)$ & & & \\
\hline $\begin{array}{c}\text { Mẫu } \\
19 \\
\end{array}$ & - & & & $I C(C t 25)$ & & & \\
\hline $\begin{array}{c}\text { Mẫu } \\
20\end{array}$ & $\begin{array}{c}\text { Shigella } \\
\text { S. } \\
\text { aureus } \\
\end{array}$ & & & $I C(C t 26)$ & $\begin{array}{c}\text { S.aureus (Ct } \\
32)\end{array}$ & & $\begin{array}{c}\text { EIEC } \\
(\text { ipaH) } \\
(\text { Ct 28) }\end{array}$ \\
\hline $\begin{array}{c}\text { Mẫu } \\
21\end{array}$ & - & & & $I C(C t 25)$ & & & \\
\hline $\begin{array}{c}\text { Mẫu } \\
22\end{array}$ & - & & & $I C(C t 25)$ & & & \\
\hline $\begin{array}{c}\text { Mẫu } \\
23\end{array}$ & - & & & $I C(C t 26)$ & & & \\
\hline $\begin{array}{c}\text { Mẫu } \\
24\end{array}$ & - & & & $I C(C t 26)$ & & & \\
\hline $\begin{array}{l}\text { Mẫu } \\
25\end{array}$ & $\begin{array}{l}\text { Salmone } \\
\text { lla }\end{array}$ & & & $\begin{array}{l}\text { IC (Ct 25) } \\
\text { Salmonella } \\
\quad(C t 21)\end{array}$ & & & \\
\hline
\end{tabular}




\begin{tabular}{|c|c|c|c|c|c|c|c|}
\hline & \multirow{2}{*}{$\begin{array}{l}\text { PCR- } \\
\text { RDB }\end{array}$} & \multicolumn{6}{|c|}{ PowerCheck $^{\mathrm{TM}} 20$ Pathogen Multiplex Real-time PCR Kit } \\
\hline Mấu & & $\begin{array}{c}\text { Multiplex } \\
1 \text { Set }\end{array}$ & $\begin{array}{c}\text { Multiplex } \\
2 \text { Set }\end{array}$ & $\begin{array}{c}\text { Multiplex } 3 \\
\text { Set }\end{array}$ & $\begin{array}{c}\text { Multiplex } 4 \\
\text { Set }\end{array}$ & $\begin{array}{c}\text { Multiplex } \\
5 \text { Set }\end{array}$ & $\begin{array}{c}\text { Multiplex } \\
6 \mathrm{Set}\end{array}$ \\
\hline $\begin{array}{l}\text { Mẫu } \\
26\end{array}$ & - & & & $I C(C t 26)$ & & & \\
\hline $\begin{array}{c}\text { Mẫu } \\
27\end{array}$ & - & & & $I C(C t 25)$ & & & \\
\hline $\begin{array}{c}\text { Mẫu } \\
28\end{array}$ & - & & & $I C(C t 26)$ & & & \\
\hline $\begin{array}{c}\text { Mẫu } \\
29\end{array}$ & - & & & $I C(C t 25)$ & & & \\
\hline $\begin{array}{c}\text { Mẫu } \\
30\end{array}$ & - & & & $I C(C t 25)$ & & & \\
\hline
\end{tabular}

Nguồn: Kết quả phân tích dữ liệu của nhóm nghiên cứu

Chỉ số chu kỳ ngưỡng (threshold cycle $-\mathrm{Ct}$ ) trên 30 mẫu thử nghiệm của bộ kít PowerCheck ${ }^{\mathrm{TM}} 20$ Pathogen Multiplex Real-time PCR Kit (Korea) đều xuất hiện ở chu kỳ thứ 25 hoặc 26, ghi nhận tính ổn định của kít thương mại này. Có hai mẫu (mẫu 3 và 20), kết quả real-time PCR xuất hiện tín hiệu dương với EIEC (ipaH), PCR-RDB ghi nhận dương tính với mẫu dò dò vi khuẩn Shigella. Các mẫu này cũng đã được nuôi cấy ghi nhận vi khuẩn mọc là Shigella (dữ liệu không trình bày), nên chúng tôi có thể khẳng định về kết quả phát hiện là Shigella trong mẫu. Kết quả này cũng cho phép chúng tôi suy luận, real-time PCR của bộ kít PowerCheck ${ }^{\mathrm{TM}} 20$ Pathogen Multiplex Real-time PCR bắt được với gen quy định độc tố (ipaH) ở cả E. coli và Shigella.

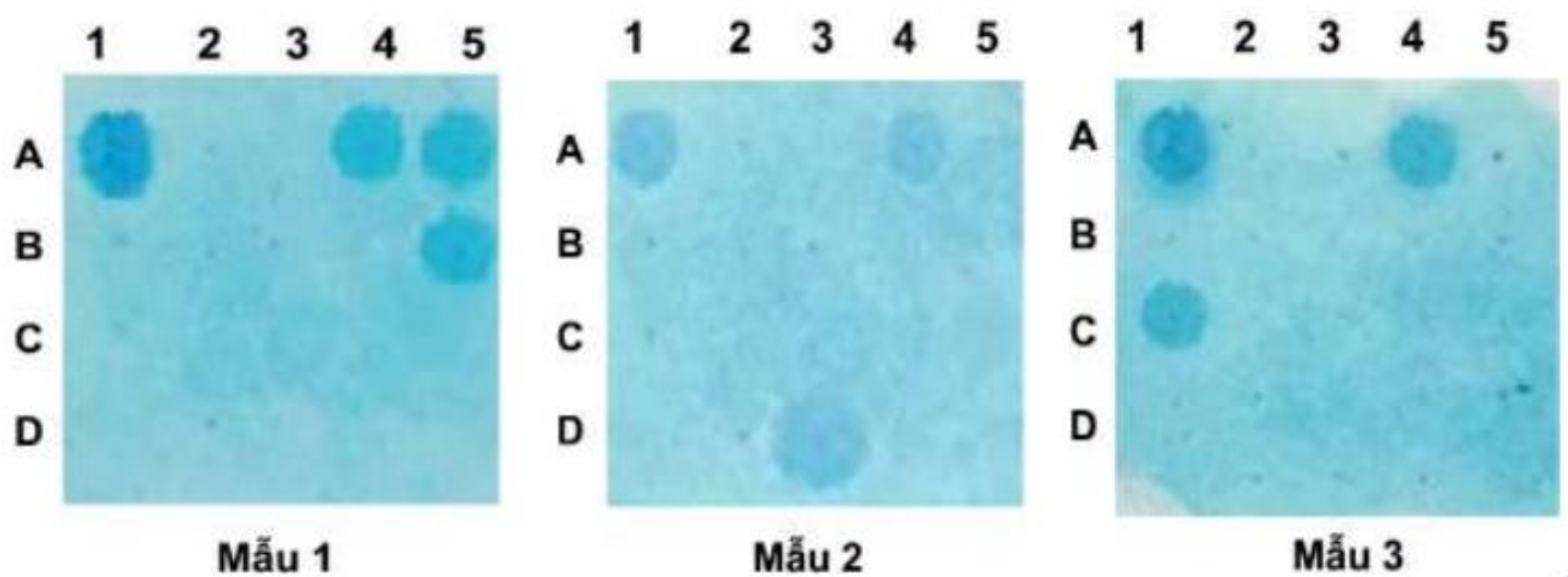




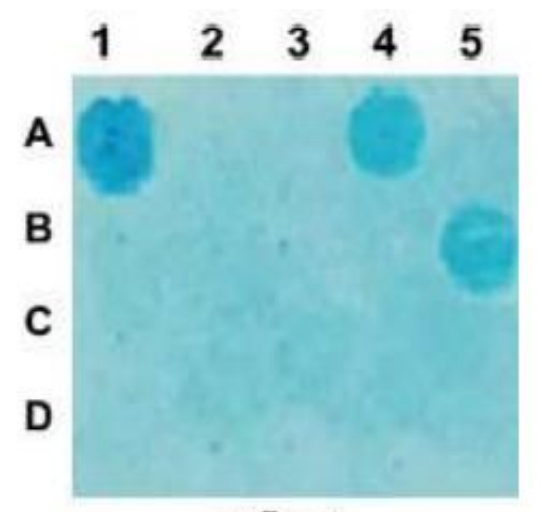

Mẫu 4

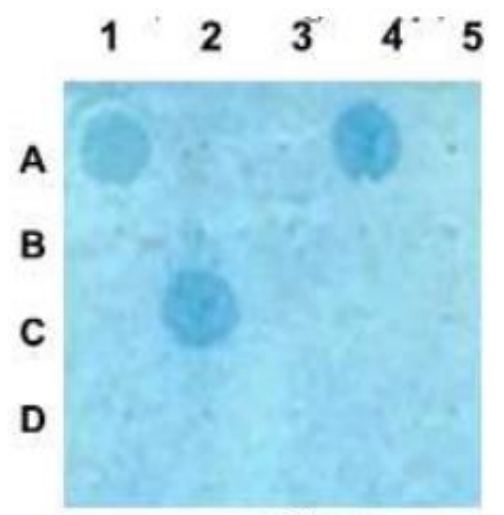

Mẫu 5

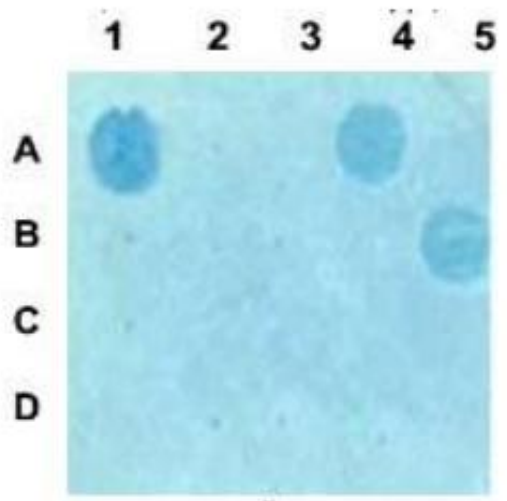

Mẫu 6

Hình 2. Kết quả PCR-RDB trên các mẫu phân 1 - 6

\section{Kết luận}

Chúng tôi đã thành công trong việc thiết kế hai mẫu dò mới để dò hai vi khuẩn Campylobacter jejuni (CJE), Yersinia enterocolitica $\mathrm{O}: 8$ (YO8), cũng như thiết kế mới các mẫu dò chứng dương $(\mathrm{P})$, chứng màu $(\mathrm{C})$ và chứng âm $(\mathrm{N})$. Các mẫu dò đều cho thấy tính đặc hiệu cao cả trên lý thuyết lẫn thực nghiệm. Quy trình PCR-RDB được công bố ở đây đã cho phép phát hiện đồng thời 14 vi khuẩn gây bệnh đường ruột, bao gồm: Bacillus cereus, Clostridium botulinum, Clostridium perfringen, Staphylococcus aureus, Listeria monocytogenes, Escherichia coli O157:H7, Salmonella spp., Shigella spp.., Vibrio cholerae, Vibrio parahaemolyticus, Yersinia enterocolitica, Brucella spp, Yersinia enterocolitica 0:8 và Campylobacter jejuni, với độ nhạy quy trình PCR-RDB đạt $10^{2}$ bản sao/ml. Quy trình được thử nghiệm trên 30 mẫu phân ghi nhận tính chính xác tuyệt đối trong xét nghiệm 14 vi khuẩn vừa nêu khi so sánh với kít thương mại của Hàn Quốc (PowerCheck ${ }^{\mathrm{TM}} 20$ Pathogen Multiplex Real-time PCR Kit). Quy trình vì vậy sẽ được tiếp tục thử nghiệm trên cỡ mẫu lớn hơn và các đơn vị thử nghiệm rộng rãi hơn, trước khi đăng ký giấy phép lưu hành sản phẩm.

\section{LỜI CẢM ƠN}

Nghiên cứu được thực hiện bởi sự đồng tài trợ kinh phí của Bộ Giáo dục \& Đào tạo, Việt Nam (B2015-32-03) và Công ty Cổ phần \& Công nghệ Việt Á.

\section{Tài liệu tham khảo}

Bao, V. N., Fries, R., Zessin, K. H., Kyule, M. N., Pinthong, R., \& Baumann, M. P. O. (2006). Salmonella and Campylobacterin broiler carcasses in Vietnam. Retrieved July 10, 2018, from http://www.sciquest.org.nz/elibrary/download/64263/T7-S12__Salmonella_and_Campylobacter_in_broiler_c.pdf

Blessmann, J., Pham, L. V., Phuong, A. T. N., Hao, D. T., Muller-Myhsok, B., Buss, H., \& Tannich, E. (2002). Epidemiology of amebiasis in a region of high incidence of amebic liver abscess in central Vietnam. The American Journal of Tropical Medicine and Hygiene, 66(5), 578-583. 
Bộ Y tế. (2009). Hướng dẫn xủ trí tiêu chảy nhiễm trùng ở trẻ em [Guidelines for the management of infectious diarrhea in children]. Retrieved July 12, 2018, from http://ampharcousa.com/tai-lieu-huong-dan-xu-tri-tieu-chay-o-tre-em.html

Carrique-Mas, J. J., Bryant, J. E., Cuong, N. V., Hoang, N. V., Campbell, J., Hoang, N. V., ... Baker, S. (2014). An epidemiological investigation of Campylobacter in pig and poultry farms in the Mekong delta of Vietnam. Epidemiol Infect, 142(7), 1425-1436.

Fredriksson-Ahomaa, M., \& Korkeala, H. (2003). Low occurrence of pathogenic - Yersinia enterocolitica in clinical, food and environmental samples: A methodological problem. Clinical Microbiology Review, 16(2), 220-229.

Fukushima, H., Shimizu, S., \& Inatsu, Y. (2011). Yersinia enterolotica and Yersinia pseudotuberculosis detection in foods. Journal of Pathogens, 2011, Article 735308.

Garin, B., Gouali, M., Wouafo, M., Perchec, A. M., Tham, M. T., Ravaonindrina, N., ... Pouillot, R. (2012). Prevalence, quantification and antimicrobial resistance of Campylobacter spp. on chicken neck-skins at points of slaughter in 5 major cities located on 4 continents. International Journal of Food Microbiology, 157(1), 102-107.

Ha, T. A., \& Pham, T. (2006). Study of Salmonella, Campylobacter, and Escherichia coli contamination in raw food available in factories, schools, and hospital canteens in Hanoi, Vietnam. Annals of the New York Academy of Sciences, 1081, 262-265.

Huong, L. Q., Hanh, T. T., Cam, P. D., \& Be, N. T. (2006). Study on the prevalence of Campylobacter spp. from chicken meat in Hanoi, Vietnam. Annals of the New York Academy of Sciences, 1081, 273-275.

Huovinen, E., Sihvonen, M. L., Virtanen, M. J., Haukka, K., Siitonen, A., \& Kuusi, M. (2010). Symptoms and sources of Yersinia enterolitica-infection: A case-control study. BMC Infectious Diseases, 10, Article 122.

Isenbarger, D. W., Hien, B. T., Ha, H. T., Ha, T. T., Bodhidatta, L., Pang, L. W., \& Cam, P. D. (2001). Prospective study of the incidence of diarrhoea and prevalence of bacterial pathogens in a cohort of Vietnamese children along the Red River. Epidemiol Infect, 127(2), 229-236.

Katherine, L. A., Thompson, C. N., Nguyen, T. V. T., Nguyen, M. N., Le, T. P. T., Tran, D. T. N., ... Simmons, C. P. (2015). The epidemiology and aetiology of diarrhoeal disease in infancy in southern Vietnam: A birth cohort study. International Journal of Infectious Diseases, 35, 3-10.

Nguyen T. V., Van, P. L., Huy, C. L., Gia, K. N., \& Weintraub, A. (2006). Etiology and epidemiology of diarrhea in children in Hanoi, Viet Nam. International Journal of Infectious Diseases, 10(4), 298-308. 
Schroeder, G. N., \& Hilbi, H. (2008). Molecular pathogenesis of Shigella spp.: Controlling host cell signaling, invasion, and death by type III secretion, Clinical Microbiology Reviews, 21(1), 134-156.

Schwan, P. (2010). Prevalence and antibiotic resistance of Campylobacter spp. in poultry and raw meat in the Can Tho Province, Vietnam. Examensarbete, 2010(4), 1-24.

Thompson, C. N., Phan, M. V. T., Nguyen, H. V. M., Pham, M. V., Nguyen, V. T., Cao, T. T., ... Baker, S. (2015). A prospective multi-center observational study of children hospitalized with diarrhea in Ho Chi Minh City, Vietnam. The American Journal of Tropical Medicine and Hygiene, 92(5), 1045-1052.

Thuy, H. T. T., Thuan, L. D., Phuong, T. K., \& Thuy, L. H. A. (2016). Identification of bacterial intestinal pathogens by a PCR-Reverse Dot Blot procedure. Journal of Science HoChiMinh city Open University, 1(17), 11-22.

Trang, D. T., Hien, B. T. T., Molbak, K., Cam, P. D., \& Dalsgaard, A. (2007). Epidemiology and aetiology of diarrhoeal diseases in adults engaged in wastewater-fed agriculture and agriculture in Hanoi, Vietnam. Tropical Medicine \& International Health, 12, 23-33.

Vinh, H. (2010). Acute childhood diarrhoea: Shigella versus Rotavirus. In The changing epidemiology, clinical syndrome and antibiotic resistance patterns of shigellosis in Vietnamese children. Milton Keynes, UK: The Open University.

World Health Organization (WHO). (2005). The treatment of diarrhoea: A manual for physicians and other senior health workers. Retrieved July 21, 2018, from https://apps.who.int/iris/bitstream/handle/10665/43209/9241593180.pdf?sequence=1

World Health Organization (WHO). (2013). Diarrheal diseases. Retrieved July 20, 2018, from http://www.who.int/mediacentre/factsheets/fs330/en/. 